\title{
Pesquisa
}

\section{DESENVOLVIMENTO DA LEITURA E DA ESCRITA ATRAVÉS DO PROGRAMA ALFABETIZAÇÃO NA IDADE CERTA - PAIC}

Cícera Pereira da Silva (1)

\begin{abstract}
Resumo
O presente estudo tem a finalidade de discutir o processo de ensino-aprendizagem da leitura e escrita dentro do Programa Alfabetização na Idade Certa - PAIC, alicerçado pelo estudo de diferentes autores relacionados ao processo de alfabetização. Esta proposta pedagógica refere-se ao ensino estruturado e sistematizado da leitura e da escrita, basicamente na classe de alfabetização. Refletimos que o desenvolvimento da leitura e da escrita não se limitam ao ensino de uma mera decodificação de símbolos ou signos, mas sobretudo, envolve uma concepção bem mais ampla no processo de apreensão e compreensão do mundo em que vivemos. Trata-se de uma rica fonte documental sobre o processo de aquisição da leitura e da escrita através de novas metodologias educacionais, assunto que deve ser cotidianamente discutido, dadas as modificações técnicas e tecnológicas que tem surgido em nível global, nesta área do conhecimento.
\end{abstract}

Palavras-chave: leitura, escrita, metodologia educacional, habilidade.

\section{Introdução}

Num contexto histórico social é relevante as questões abordadas diante do ensino da leitura e da escrita nas classes de $1^{\mathrm{a}}$ séries, hoje denominadas de $2^{\circ}$ ano do ensino fundamental I. No processo de alfabetização, a leitura e escrita tem sido constantemente refletidas por estudiosos da educação. Tem sido motivo de preocupação, a quantidade de alunos que 
chegam ao $5^{\circ}$ ano do ensino fundamental sem conseguir ler com a fluência adequada a essa seriação, e que se perpetuam durante a vida escolar da criança, dificultado o acompanhamento do processo de ensino-aprendizagem. O presente estudo busca refletir sobre o desenvolvimento da leitura e escrita na idade certa, programa de ensino estabelecido pelo PAIC (programa de Alfabetização na Idade Certa).

A leitura e escrita constituem-se de um amplo sistema de representação da linguagem, convertendo assim sua aquisição numa aprendizagem conceitual, ou seja, o sucesso ou fracasso da alfabetização depende muito do nível de evolução conceitual da criança que chega à escola. Caso apresente um processo de construção bem evoluído, a tendência é um bom processo alfabetizador. Caso não tenha experiência anterior de contato com livros, revistas, jornais, se não ouviu nem leu histórias, não lhe foi oferecido a oportunidade de ter contato com a leitura e escrita, as perspectivas de sucesso diminuem. Nesse sentido a criança chega em condições precárias de compreender e acompanhar o trabalho de alfabetização que a escola the oferece.

As escolas muitas vezes não procuram averiguar o nível de evolução conceitual, para que possam partir do ponto de aprendizado que a criança se encontra. Dessa forma, torna-se necessário um trabalho sistemático, onde a criança possa avançar gradativamente rumo a uma alfabetização adequada.

No construtivismo de Emília Ferreiro, a criança é vista e analisada sobre esse aspecto conceitual, ela passa a ser sobre tudo, o sujeito principal no processo de aprendizagem. $\mathrm{O}$ professor, nesta filosofia educacional, faz parte de uma aprendizagem coletiva, um mediador, cabendo a ele colocar a criança em contato com o meio mais amplo. Nos primeiros anos de escolaridade o educador é o veículo mais importante para transmitir informações e ajudar o aluno. Quanto mais básica e elementar uma série (curso) mais estruturadas as ferramentas metodológicas devem ser, para ajudar o aluno a aprender.

Nessa proposta pedagógica a escola enquanto instituição precisa sair de seu limite físico, atravessando assim os muros e trazendo a sociedade para dentro dela. O professor precisa romper o estreitamento simbólico usado como substituto, e tomar a leitura como ponto de partida para a criança rever o real e o concreto das relações sociais.

Nesse sentido, a ação do professor é de criar condições favoráveis para o saber e a aprendizagem será a ação adequada que resulta no aluno o conhecimento. Com base nesse ponto de vista Telma Weiz apresenta em: o diálogo entre o ensino e a aprendizagem, que o professor é que precisa compreender o caminho de aprendizagem que o aluno está percorrendo naquele momento e em função disso, identificar as informações e as atividades 
que permitam a ele avançar no patamar de conhecimento que já conquistou para outro mais evoluído. Portanto, não é o processo de aprendizagem que deve se adaptar ao ensino, mas o processo de ensino é que tem que se adaptar ao de aprendizagem.

O tema em pauta está essencialmente apoiado na proposta pedagógica estabelecida pelo PIC. (programa de Alfabetização na Idade Certa). Sendo que a proposta de ensino aderida ao $2^{\circ}$ ano do ensino fundamental I baseia-se em alfabetizar pelo método fônico.

Este método, não se presta apenas a ajudar o aluno a escutar no sentido físico, como também a prestar atenção no sentido psicológico e cognitivo às considerações contidas num texto, adquirindo competências essenciais de discriminação que possibilitarão uma leitura e, sobretudo uma escrita mais precisa.

Em suma aprender ler e escrever constitui na vida da criança, um momento importante em seu desenvolvimento. Entretanto, há um longo processo a ser percorrido até que esse aprendizado se concretize.

\section{Conceituando métodos de alfabetização}

Durante os últimos trinta anos, na história da educação foram realizados notáveis crescimentos no campo teórico e prático do processo de alfabetização. Tais avanços estão relacionados, sobretudo no conhecimento científico, métodos, técnicas, políticas públicas, instrumentos de diagnóstico e avaliação que foram desenvolvidos e testados. Nesse eventual contexto a alfabetização saiu do terreno empírico e do tentar dar certo e entra num domínio da ciência, no qual resta ainda muito a conhecer, mas muitos desses conhecimentos foram produzidos e hoje podemos dizer que constituem um relativo saber consolidado.

Ao longo desses anos o professor alfabetizador procurou o conhecimento pedagógico num livro que era a ele destinado, procurando assim manter em todos os momentos, o foco na aplicação "prática", como se o livro fosse uma mera receita de bolo que deveriam seguir sua ordem sem que procurasse conhecer a realidade que o aluno vive e muitas vezes a bagagem que ele traz, se traz, então durante muito tempo a expressão aprendizagem se referia a estudar sem considerar o ritmo de desenvolvimento da criança entendendo que tal processo de alfabetização apenas codificar e decodificar sem perceber que através deste conceito é que a leitura tornava-se desenvolvimento. Pois se iniciava do abstrato para o concreto explicaria como se processava a construção do conhecimento na leitura e na escrita anteriormente. 
Hoje trabalhamos com um dos melhores programas de ensino no caso o PAIC, criado pelo governo do Estado do Ceará para atender as necessidades da alfabetização na idade ceta. Porém as dificuldades enfrentadas em sala de aula são alarmantes, pois o baixo índice de rendimento escolar nas séries iniciais deixa sempre algo a desejar.

Para tanto, pretende-se fazer um aprofundamento amplo e específico a respeito do problema, procurando assim fornecer subsídios teóricos e metodológicos que sirva de uma eventual reflexão para a prática pedagógica.

Os educadores alfabetizadores precisam estar a par do que anda acontecendo em relação ao processo de alfabetização no qual estão inseridas nossas crianças da sede municipal e no que diz respeito á leitura e a escrita compreendendo que o processo dessa caminhada vem de um longo período, onde procura se estruturar externamente o pensamento infantil sobre tudo no que está relacionado à leitura elemento essencial para a eficácia do problema que tato preocupa os profissionais inseridos nesse contexto.

Existe uma crença generalizada que o sucesso da alfabetização depende de um bom método, ou de uma boa cartilha. Porém isso começa ser questionado, pois sabemos que os métodos em sua maioria deixaram muito a desejar. Pois levavam a criança a praticar uma simples memorização, ou seja, a repetição de pedaços de palavras, ou frases sem nenhum significado. A utilização das cartilhas pressupõe que a classe seja homogênea. Isso na verdade chega a ser artificial, como estão atendendo as necessidades dos alunos com ritmos diferentes?

Porém vale ressaltar, que o método metafônico associado ao programa alfa e Beto de alfabetização idealizado e produzido pelo autor João Batista Araújo, atendendo as necessidades estabelecidas pelo PAIC (Programa de Alfabetização na Idade Certa).

Desde o ano de dois mil e oito, o programa Alfa e Beto de Alfabetização vem sendo ministrado na Escola Joaquim Rufino de Oliveira, Município de Altaneira, Ceará. Como educadora, leciono nas salas de segundo ano, trabalhando o método metafônico, termo que foi utilizado para ressaltar duas características principais deste programa, a saber: a ênfase no ensino das relações entre sons e letras e, ênfase na metacognição. Pode-se dizer que o processo de alfabetização é eminentemente cognitivo, exigindo que o aluno a todo o momento reflita sobre o que está fazendo e o que está aprendendo.

Para compreendermos melhor o processo de ensino a partir de métodos faz-se necessário um breve comentário sobre os mais conceituados até então, fazendo um fechamento com o qual acredito que o método hoje trabalhado na referida escola seja o que 
possibilitará um reflexo maior no que se diz respeito à aquisição da leitura e da escrita como papel relevante da sociedade.

Ao longo dos anos, se perguntavam perpetuamente: que métodos de alfabetização utilizar? O que diferencia um método de alfabetização do outro?

$\mathrm{Na}$ história da pedagogia exames cuidadosos revelam que rigorosamente só existiram três métodos de alfabetização: o alfabético o fônico e o global. Na verdade, esses métodos de alfabetização sempre trataram fundamentalmente das habilidades e competências relacionadas a aprender a ler. Pois tudo o que conhecemos sobre alfabetizar são variações em torno desses três métodos básicos de alfabetização.

O método mais antigo inventado pelos gregos a cerca de dois mil e quinhentos anos, foi o método alfabético, junto com o alfabeto. $O$ ponto de partida para o ensino aqui era a letra. Primeiro aprendia-se as letras do alfabeto e as ia juntando para formar palavras. É o conhecido método bê-á-bá que de certa forma ainda vigora em algumas escolas tanto públicas como particulares que herdaram essa tradição. Esse método supõe que a criança aprenda fazer uma união bê $+\mathrm{a}=$ ba. Mas na basta saber o nome da letra, ou de seus sons, para aprender a ler. A união de uma letra não é representar um som, mas um fonema. Pois fonemas são unidades abstratas que nos permite distinguir. Por exemplo: mala e tala quando falamos. $\mathrm{O}$ fonema corresponde às consoantes na é pronunciável sozinho, sem uma vogal e por isso não constituem um som.

O método alfabético em si representa uma compreensão imperfeita do princípio alfabético. Na verdade, o conceito de fonema só começa a ser estudado em meados do século XIX. Onde desenvolveram estudos psicolingüísticos que despertavam para a importância do educando descobrir o princípio alfabético, que significa compreender a relação entre fonema e grafemas. Surgiam aqui insatisfações com o método alfabético mesmo antes de aprofundados estudos sobre o assunto. (OLIVEIRA p.37)

Desde o século XVII, pedagogos começaram a utilizar o método global - A idéia aqui não se baseia em conhecimentos psicolingüísticos, mas na importância atribuída a motivação - pois esses métodos partiam sobretudo de frases escritas com palavras conhecidas pelas crianças focalizando progressivamente em unidades menores, palavras, sílabas e até grafemas. Como exemplo pode-se citar o método Paulo Freire, herdeiro dessa tradição no que ele denomina de palavra-chave.(OLIVEIRA p.38)

Os conhecimentos inicialmente desenvolvidos pelos lingüistas, e logo após retornados pelos psicolinguístas, deram origem ao desenvolvimento do chamado método fônico, ou métodos fônicos. Método fônico - é o que ensina de forma explícita, a relação 
entre grafemas e fonemas. "Esse ensino permite a criança descobrir o princípio alfabético e progressivamente, dominar o conhecimento ortográfico próprio de sua língua”. (OLIVEIRA p.72)

Em o livro ABC do alfabetizador o autor do mesmo, João Batista de Oliveira destaca que: todas as evidências científicas coletadas nos últimos trinta anos demonstram de maneira inevocada, a superioridade dos métodos fônicos obre os demais. Onde a maioria dos pises do mundo e todos os desenvolvidos que usam a linguagem alfabética preconizam o uso desses métodos em suas diretrizes curriculares nacionais.

O método metafônico apresenta em si descobertas e conceitos importantes sobre alfabetização. Não se identifica com outro método em particular. Ele consiste em descobertas que assinalam todos os aspectos que pesquisas modernas sobre alfabetização recomendam para a prática escolar. Recomendações essas que incluem diversos aspectos contidos no programa Alfa e Beto. De modo quais serão utilizados para ilustrar e exemplificar os conceitos na media em que forem sendo apresentados. Essas descobertas vêm sugerir que um programa de alfabetização deva contemplar sobre tudo, o ensino sistematizado, organizado e estruturado nas seguintes competências: fundamentos: consistência fonológica, familiaridade com livros e textos impressos e metalinguagem. Pré-requisitos: consciência fonêmica e princípio alfabético.(CAPOVILLA. P.93)

A relação entre as competências de alfabetização são complexas, pois os termos fundamentais, pré-requisitos, requisitos e desenvolvimentos não implicam uma hierarquia rígida, mais sugerem uma interdependência. Mais que isso, implicam que cada uma delas precisam ser ensinadas e desenvolvida de forma internacional, como foco instrucionacional específico para cada competência. (ABC do alfabetizador 2003 p. 24)

As características básicas de um programa de ensino precisam ser compartilhadas por todos os envolvidos no processo de alfabetização, para que possamos compreender que a leitura é decorrente de um processo que precisamos saber o que realmente significa a expressão "ler bem". Sabemos e compreendemos que ler bem envolve automaticidade, fluência e compreensão, sendo assim o ensino estruturado no processo de construção da leitura e escrita permite o aluno ordenar, classificar e relacionar um acervo muito maior de conhecimento relevante. Cabe aqui ressaltar que segundo, Emília Ferrero, em pesquisas realizados sobre o processo de construção da leitura e escrita, constatou-se que o mesmo, constituiu-se num sistema de representação de linguagem, e a sua aquisição é decorrente de uma aprendizagem conceitual, diferenciada daquela compreensão que anteriormente abordava 
esse sistema sobre o prisma de uma simples conversão das unidades sonoras em unidades gráficas.

Segundo Ferrero (1991p.49), “... o processo de alfabetização tem que ser visto do ponto de vista de quem aprende(a criança) e não daquele que ensina (professor). Com esta nova compreensão sobre o sistema de leitura e escrita, impõe-se ao professor a necessidade de um evidente maior acervo de conhecimentos. A criança ao alfabetizar-se reinventa o sistema de representar a língua escrita através de formulação de hipóteses, as quais vão sendo superadas progressivamente, à medida em que a criança avança no seu desenvolvimento gráfico. Cabe a escola renovar suas propostas pedagógicas, a fim de atualizar-se às novas perspectivas metodológicas educacionais da alfabetização.

A trajetória da psicogênese da alfabetização vem sendo percorrida por Emília Ferreiro, desde 1974, através de pesquisas feitas com equipe em Buenos Aires, posteriormente em Genebra e depois no México.

Uma proposta didática é muito mais do que uma receita. Ela exige, entre outros. Pré-requisitos, a sua recriação e cada vez que é aplicada, como todo ato pedagógico verdadeiro. Traça princípios apoiado na prática concreta de muitas experimentações contratadas com todos os teóricos que as expliquem. (PILLAR,1990).

A princípio, pode-se constatar que no primeiro ano de escolarização da criança as letras não possuem nenhum significado real para elas. São apenas riscos, que nada tem a ver com qualquer expressão e alguma realidade. Nessa primeira fase, a leitura da realidade é feita através de desenhos, gravuras e fotos, associando assim às imagens a capacidade de expressar aspectos do real. Somente depois é que a criança apresenta condições de aprender, o verdadeiro sentido que as letras podem formar para uma compreensão melhor sobre os elementos da alfabetização. Isso começou ser aprofundado e bem escrito quando o professor possibilita um amplo acervo escrito, para que a criança possa então ir se adaptando ao processo contínuo de adquirir aos poucos o desenvolvimento da leitura e da escrita.

É preciso considerar que nem todos os alunos têm os mesmos interesses ou habilidades, nem aprender da mesma maneira nem num mesmo tempo, o que a maioria das vezes exige uma atenção especial por parte do professor a um ou a outro aluno, para que assim todos possam ser integrar no processo de aprender a partir do conhecimento das 
diferenças entre os educandos fruto do processo de socialização e do desenvolvimento individual, seja possível conduzir um ensino palpado no foco da aprendizagem.

$\mathrm{Na}$ explicitação dos PCN'S (Parâmetros Curriculares Nacionais), “a opção pedagógica contribui com tal desenvolvimento, entre outras formas afirmando claramente seus princípios éticos, incentivando a reflexão e análise crítica de valores, atitudes e tomadas de decisão e possibilitando o conhecimento de que a formulação de tais sistemas é fruto de relações humanas historicamente situadas".

Alguns teóricos da alfabetização defendem a idéia de que a leitura é algo natural as pessoas, da mesma forma que a fala. Se aprendermos a falar naturalmente no contexto das interações sociais, diz-se, nada mais natural do que aprender a ler "naturalmente", no convívio com livros e leituras destaca (PINHEIRO, 1994).

Em linhas gerais cada criança chega à escola com diferentes experiências, conhecimentos e habilidades relevantes para iniciar o processo de alfabetização. $\mathrm{O}$ professor deve está atento para que todos os seus alunos possam adquirir todas essas competências, de forma aplicada para aproveitar plenamente a experiência da alfabetização. Sabe-se que quanto mais e melhor o educador conhece seus alunos será maior a facilidade para promover o desejo ajuste entre aluno e a escola, e vice-versa, sem chegar a confundir domínio (respeito) com autoritarismo.

Nesse caso, o processo de alfabetização será favorável quando toda a equipe escolar se une para dar início a esse processo, pois acima de tudo precisa-se compreender que o aluno e professor não devem andar sozinhos, mas em parceria com roda a sociedade escolar.

Alfabetização é uma brincadeira, é um jogo de decifração. A poesia e a boa literatura também o são, o poeta e o escultor brincam com as palavras para comunicar as suas idéias. (PROLETRAMENTO, 2007)

O brincar aqui se refere basicamente ao caráter lúdico que deve ser refletido nas práticas docentes. Pois brincar no que se refere ao processo de alfabetização é coisa séria, requer toda atenção, regras claras, muita repetição, um desafio a ser superado e uma curiosidade infinita para explorar as possibilidades do real. No caso do alfabeto, trata-se de aprender e explorar múltiplas possibilidades que se abrem com suas combinações. Ex. a partir de uma determinada proposição a criança pode combinar essas letras e formar inúmeras outras palavras com essas mesmas letras mudadas de posição. É por isso que todas as atividades 
devem ser apresentadas dentro do caráter lúdico e da busca de decifrar os segredos desse código.

No caso da alfabetização, João Batista destaca dois contextos relevantes. O mais relevante imediatamente é o alfabeto - o aluno está curioso e motivado para entender os segredos de funcionamento do código alfabético. Daí a importância de inundar a sala de aula e as atividades de leitura e alfabetização com letras, músicas, brincadeiras e atividades em torno do alfabeto. Um contexto relevante são os textos e livros, nas quais o aluno ver a utilização do alfabeto para fins de comunicação. Pois além da decodificação o processo de alfabetização inclui o desenvolvimento da fluência da leitura e da escrita foco central da alfabetização.

Dentre os métodos de alfabetização e os estudos envolvidos nessa lógica vale ressaltar que Paulo Freire em entrevista concedida a Nilcea Delandré, em 1993. Declarou que não era nem se considerava especialista em alfabetização quando propôs a metodologia que se tornou conhecida como método Paulo Freire.

O processo de alfabetização requer estratégias adequadas para o ensino das várias competências, professores capacitados e, um acervo de materiais adequados. Não é nada que se improvise, além disso, são necessários cuidados, incentivos e contextos que compensem o contrabalançar das dificuldades e desafios próprios de uma alfabetização tardia. Também será necessária uma avaliação objetiva e científica, caso contrário, perpetuam-se teorias e metodologias sem eficácia comprovada.

Acreditamos que o sucesso de qualquer esforço educacional repousa numa alfabetização eficaz das crianças em seus primeiros anos escolares e, por que não dizer, entre os seis ou sete anos de idade. Um atraso neste processo pode significar prejuízo e danos quase que irrecuperáveis.

\section{Aquisição da Leitura e Escrita pelo Método Fônico}

Durante muito tempo, procuramos vivenciar o fenômeno da habituação. Por exemplo, somos tão viciados em ouvir forró, que nem prestamos atenção. O rádio pode tocar esse tipo de música por horas e nem sentimos que estamos ouvindo. Do mesmo modo aconteceu e ainda acontece com alunos em processo de aprendizagem, onde a habituação significa que o estímulo deixa de chamar a atenção do educando muito cedo. 
O fenômeno contrário é o da busca de novidade. Se a música muda para clássica ou gospel, você sente a diferença e volta a prestar atenção. É isso que precisa ocorrer para que haja aprendizagem. A habituação ocorre quando deixamos de prestar atenção a estímulos repetitivos, muito familiares. A busca de novidade, ocorre quando voltamos a prestar atenção a um estímulo novo ou percebido como novo. É o que acontece com crianças em processo de alfabetização.

O professor das séries iniciais, tem como objetivo principal ajudar o aluno aprender a ler e a escrever com autonomia, isto é, de maneira fluente. Claro que o mesmo deve estar consciente de que a atenção das crianças de sete anos é de certa duração e a capacidade de autocontrole nessa idade é muito difícil. Daí a necessidade do educador mudar de atividade com certa rapidez, permitindo que o aluno não se habitue a atividades repetitivas, enquanto ele percebe ou busca novidade no exercício, ele está em condição de aprender. Depois que ele se habitua, tudo vira ruído, e ele passa a se desinteressar por essa atividade.

O programa Alfa e Beto destina-se a alfabetização de crianças nas séries iniciais do ensino, sendo flexível, podendo assim ser implantado ao longo do primeiro e segundo anos letivos. É estruturado, isso facilita e organiza tanto a vida do aluno quanto do professor, permitindo a direção da escola o acompanhamento, controle e avaliação das atividades aplicadas. O material utilizado no programa atende todas as necessidades de uma alfabetização, pois há materiais para alunos, professores, para a classe e para a escola.

Quanto a sua implantação, depende sobre tudo do diretor da escola, de sua equipe e dos professores. A secretaria de educação oferece apoio para a direção e para os educadores ao longo do processo de implantação sendo que antes da implantação, o diretor da escola e a equipe pedagógica do programa deve responsabiliza-se por assegurar capacitação aos professores, isto é, garantindo que eles possuam: informações necessárias e suficientes sobre o programa, segurança para usar materiais do programa e informações estão contidas nos dvds e manuais que acompanham a implantação do programa, seguindo de orientação sistemática e completa.

A capacitação de professores no programa, trabalha simultaneamente dimensões teórica e prática, levando o professor a compreender melhor os fundamentos e competências trabalhadas em atividades propostas para as rotinas pedagógicas na melhoria do aprendizado dos alunos.

Mesmo com métodos reconhecidamente eficazes, formar leitores, não é algo comum, nem tão pouco seguir receitas prontas e acabadas, mas é preciso que a prática de leitura seja freqüente, todos os dias e com muita empolgação. A leitura é uma prática social fundamental 
para se entender melhor o mundo. Algumas descobertas interessantes a respeito do assunto apontam alguns caminhos. Muitas vezes costumamos ouvir que o significado de um texto é construído pelo leitor, a partir da ativação de seus conhecimentos para interpretar o que está escrito.

Quando lemos um texto, é importante atribuirmos um significado a ele, relacionando os seus componentes com nossos entendimentos e sentidos, ou seja, o texto só faz sentido quando se articula com as informações que o leitor possui. Assim ler, palavras é muito mais do que converter letras em sons, é atribuir significados às palavras para que possamos entender o mundo.

A educação precisa proporcionar ao indivíduo um crescimento pessoal, possibilitando que ele se integre socialmente em determinado grupo. A escola tem como finalidade tornar esse ser pensante, ativo, capaz de procurar mudanças contínuas, acentuando-se mais na profundidade da qualidade de ensino onde o processo de socialização se inicie na alfabetização, período adequado para aprender ler, escrever e fazer uso dessa aprendizagem.

Atualmente no campo da alfabetização, existe um razoável grau de consenso sobre princípios, teorias e métodos que constituem o paradigma científico de alfabetizar. A discussão de métodos de alfabetizar na maioria dos países industrializados, os estudos sobre alfabetização e a atualidade dos currículos e programas escolares, levou a uma revisão profunda das questões relacionadas com a alfabetização e conseqüentemente, com os métodos de alfabetizar.

No estado atual de conhecimento, evidências experimentais e empíricas são unânimes em reconhecer a superioridade dos métodos fônicos no ensino da decodificação. Neste estudo, vamos compreender método fônico como qualquer método que ajude o aluno fazer relação entre fonemas e grafemas.

Há diversas maneiras e formas de aplicar métodos fônicos, mas nem todas são igualmente eficazes. De modo geral, há evidências científicas abundantes e não contestadas sobre os seguintes aspectos: tanto no plano científico quanto de aplicações concretas, o método fônico apresenta resultados superiores aos demais métodos. Os métodos fônicos geralmente beneficiam todos os tipos de alunos, mas são particularmente mais eficazes com alunos em dificuldades de leitura e escrita. "São mais eficazes quando ensinados de forma sistemática e não de forma casual, também são mais eficazes quando utilizam técnicas de síntese de fonemas". (MANUAL DO PROFESSOR, p.16).

Em síntese o uso do método fônico não ocorre de forma abstrata, ele se dá basicamente através da utilização de materiais didáticos diversos - uso de letras, alfabetos, 
atividades que associam letras e sons, palavras impressas em cartões e cartazes, textos desenvolvidos ou escolhidos por critérios semânticos e morfossintáticos. Esses materiais se encontram em forma de orientações, fichas e lista de palavras, ou sistematizadas em manuais de alfabetização.

Grande é a importância do ensino fundamental na sociedade atual, onde competências e habilidades no processo ensino aprendizagem precisam ser vencidas muito cedo, para que não haja um retrocesso na educação. Pois grande é a preocupação de profissionais envolvidos nesse contexto alfabetizador.

Educação é um processo que dura toda a vida. Ensino é uma pequena parte da educação, mas que verdadeiramente precisa ser orientada, para que o homem em sua função possa conseqüentemente ser um verdadeiro cidadão.

Como foco central da alfabetização o desenvolvimento da fluência em leitura e escrita tem se tornado a essência de tais competências adquiridas no mundo contemporâneo, cabendo aqui definir alguns conceitos básicos a seguir: alfabetização e letramento.

O primeiro refere-se basicamente ao domínio do código alfabético. No processo de leitura, isso significa a capacidade de extrair os fonemas que constituem o som das palavras, e a partir daí, identificar o seu significado. Já no processo da escrita significa ser capaz de transcrever os fonemas das palavras em sinais gráficos, ou seja, os grafemas ou letras além da decodificação que constitui o foco central da alfabetização, tal processo também inclui o desenvolvimento da fluência da leitura e da escrita.

O segundo é um conceito que se refere ao retorno da alfabetização ou ao contexto em que ela se realiza. (OLIVEIRA, p.7).

Do ponto de vista das competências de leitura em linhas gerais a partir da ciência cognitiva da leitura, esse termo corresponde a dois conjuntos de competências. Nas fases iniciais da alfabetização refere-se a familiaridade do educando com o mundo dos livros e das letras. Nesse sentido, o processo de letramento inicia-se desde os primeiros sinais de vida e não se encerra com o processo de alfabetização. Em outros sentidos o termo letramento refere-se ao processo de alfabetização definido como a fase de aprender a ler, o restante da escolaridade tem como ferramenta principal ler para aprender. Desta forma o desenvolvimento das competências básicas para esse processo se dar muito antes da escolaridade com acesso a livros, letras e seu próprio nome. No entanto para o desenvolvimento das competências necessárias para a compreensão do que ler pode se dar antes da escolaridade, mas é na escola que o aluo adquire as ferramentas básicas para compreender o que lê. 
É incrível, fantástico e mágico que as vinte e seis letras do alfabeto possam ser combinadas de tantas maneiras, que elas possam encher com livros estantes gigantescas, levando-nos para um mundo que nunca tem fim e nunca cessará de crescer e se expandir, enquanto na terra existirem humanos. (A BIBLIOTECA MÁGICA DE BIBBÍ BOKEM), p.148.

O processo de aprendizagem permite transferir o conhecimento a novas situações, em contexto geral contribui para aprender na medida em que motiva o aluno. Daí a importância de inundar a sala de aula e as atividades de leitura e alfabetização com letras, músicas, brincadeiras e atividades em torno do alfabeto. $\mathrm{O}$ ensino, os desafios, exercícios e atividades devem ir além do texto e do contexto e exigir do aluno capacidade de abstração cada vez mais elevada.

No entanto a contextualização é ponto de partida, mas não pode ser o ponto de chegada do ensino, mas o ponto de chegada deve ser exatamente o contrário, onde o aluno seja capaz de aplicar o novo conhecimento a novas situações, a novos contextos. Pois muito relevantes são os textos e livros nos quais o educando vê a utilização do alfabeto para fins de comunicação e que é enfatizado pelo termo letramento.

Em síntese o paradigma da ciência cognitiva da leitura no processo de aprendizagem, embora centrado no conceito da decodificação, inclui os seguintes conjuntos de competências: competências da leitura e competências da escrita.

O primeiro conjunto de competências aqui refere-se a leitura. Princípio alfabético, código alfabético, fluência, vocabulário e compreensão. Já o segundo refere-se às competências de escrita. Caligrafia, ortografia, sintaxe e redação.

No processo de ensino aprendizagem muitos são os desafios enfrentados pelos nossos alunos tanto nas competências que se referem a leitura quanto a escrita.

Um dos primeiros desafios é adquirir o princípio alfabético que significa adquirir o conceito de que as letras representam o valor sonoro das palavras. O aluno precisa desenvolver uma consciência dos fonemas, para isso ele deve ser capaz de identificar os elementos sonoros mais elementares das palavras, os fonemas, fazendo também o conhecimento das letras, suas formas e nomes.

O segundo desafio é aprender o código alfabético que significa saber o valor que cada grafema (letra ou dígrafo) tem numa palavra. O primeiro passo consiste em identificar pelo menos um grafema para cada fonema. Nesse caso o aluno vai aprendendo aos poucos 
que uma mesma letra pode representar mais de um fonema e que esse mesmo fonema pode ser representado por mais de um grafema.

O terceiro desafio é aprender o código ortográfico, em primeiro momento o educando aprende a identificar pelo menos uma letra (ou dígrafo) para representar os fonemas. Com isso e aos poucos aprende a forma ortográfica correta.

Um outro desafio é a fluência, competência central na aprendizagem das crianças, que significa a capacidade de ler de forma correta, sem erros, com uma determinada velocidade, qualidade denominada de entonação, ou seja, a fluência é a parte que liga à compreensão. E é ela que alimenta "o cérebro com informações suficientes para que ele possa processar o significado, a sintaxe e o sentido daquilo que lemos e escrevemos". (OLIVEIRA, p.17).

Segundo João Batista Oliveira e Juliana Cabral, destacam que a leitura lenta e com erros não permite a compreensão do que se lê. O desenvolvimento da fluência é assunto tratado até o final do ensino fundamental, mas ao final do processo de alfabetização o aluno já deve ser capaz de ler pelo menos 60 palavras por minuto em texto conectado. Esse é o nível máximo de leitura que permite ao aluno compreender o que lê.

Um outro desafio é o vocabulário que é a ferramenta principal que permite a compreensão. $\mathrm{O}$ vocabulário nos permite articular a sintaxe e nos levam à compreensão. A criança adquiriu seu vocabulário atual ouvindo conversas, conversando, ouvindo histórias e elaborando mentalmente esses conteúdos a partir daí. A contribuição da escola consiste em dar à criança possibilidades de aprender vocabulários a partir do que ela mesma lê. Isso se dá, por um lado, pela alfabetização e de outro pela aprendizagem de estratégias e habilidades para aprender o sentido de novas palavras a partir do que a criança lê. Para isso a leitura é a maior e mais eficaz estratégia para aprender o sentido de novas palavras. No entanto, para ler, o aluno precisa, primeiro aprender a ler e ler com fluência.

Um dos últimos desafios na aquisição da leitura é a compreensão. Compreensão essa de textos que envolve um conjunto de conhecimentos, habilidades e competências que se iniciam muito cedo e se desenvolve ao longo da escola e porque não dizer ao longo da vida. Como o aluno ainda tem poucos recursos para ler nas duas séries iniciais, a aprendizagem dessas estratégias se faz pela mediação do professor, que é um leitor para os alunos e lhes ensina a "ler para aprender" mesmo antes deles serem capazes de ler com autonomia.

Quanto às competências da escrita há pelo menos quatro que estão associados a esse processo com diferentes níveis de complexibilidade. No processo de alfabetização a atenção do aluno está concentrada em decifrar o alfabeto e no caso da escrita, em procurar na memória 
a forma da letra que corresponde ao fonema que ele quer representar. Até que automatize esse processo muitas são as dificuldades para cuidar dos desafios da escrita.

Apropriar-se do sistema de escrita depende fundamentalmente de compreender um de seus princípios básicos: os fonemas são representados por grafemas na escrita. (...) é preciso, então que o aluno aprenda as regras de correspondência entre fonemas e grafemas, a partir de trabalho sistemático em sala de aula. (PRO-LETRAMENTO, FASCÍCULO 1, p.32).

Para que o processo de alfabetização de nossas crianças sejam favoráveis no seu desenvolvimento ao longo da vida, precisamos refletir sobre as convenções do sistema alfabético português de modo que possamos desenvolver uma percepção da relação entre os sons da fala, ou fonemas, e as letras ou grafemas, que os reproduzem na escrita.

Essas convenções foram definidas ao longo de vários séculos, a medida que progrediam os estudos sistematizadores da gramática normativa.

O domínio da ortografia ocorre gradualmente orientado e quanto mais oportunidades temos de observar a língua escrita, refletindo sobre suas características, mais domínio vamos adquirindo sobre as convenções que a regem. As crianças levam muito tempo para automatizar as regras ortográficas. Seus domínios dessas convenções vão se consolidando depois que tiverem muito contato com a infinidade de material impresso a ela favorável.

Durante o processo de alfabetização os desafios da escrita são muitos, uma vez que escrevemos para se comunicar. Por tanto, a escrita só preserva sua função se o leitor for capaz de ler e entender o que foi escrito.

\section{PAIC: Fundamentação e Objetivos}

Alfabetizar é uma tarefa árdua, que requer um longo processo com ações e metas estabelecidas que visem uma educação de qualidade.

Par definir alfabetização temos que levar em conta o fenômeno que lhe dar origem e que se refere a uma atividade relacionada à decifração de um código. Segundo Telma Weiz (2000), alfabetizar refere-se ao alfabeto. O alfabeto é um código, ou seja, um mecanismo de conversão de um código de comunicação oral em outro tipo de registro, o registro escrito desta. 
Mas o que o alfabeto codifica? O alfabeto codifica os fonemas em sinais chamados grafemas. Essa atividade se chama decodificar, compreender as regras que regem o funcionamento desse código. Pois decodificar consiste em aprender a transformar fonemas em grafemas, ou seja, a especificidade da alfabetização aqui definida reside em extrair a pronúncia ou o sentido de uma palavra a partir de sinais gráficos, ou seja, a capacidade de ler e em decodificar graficamente os sons correspondentes a uma palavra, a capacidade de escrever. O que é específico à alfabetização não é a compreensão do sentido da palavra, pois essa o leitor já traz a partir de seus conhecimentos e experiências anteriores. O que é específico é a capacidade de identificar a palavra.

O entendimento desse conceito é essencial para o progresso dos conhecimentos teóricos e práticos sobre alfabetização. Mas isso, não basta, pois o objetivo da alfabetização na é ensinar a pessoa a ler palavras, mas compreender textos, a partir da leitura de textos e contextos.

Termos como alfabetização funcional, leitura de mundo e letramento, são usados por diferentes autores para enfatizar aspecto do ensino de leitura escrita, que de resto, não se esgota, nem substituem a importância da alfabetização. Trata-se de um processo que envolve outras competências como o desenvolvimento da fluência, vocabulário e aquisição de técnicas de compreensão de leitura.

No entanto o PAIC (Programa de Alfabetização na Idade Certa). É um programa que tem dado bons resultados, contudo só abrange as séries iniciais do ensino fundamental. $\mathrm{O}$ programa estabelece o compromisso dos municípios com a alfabetização de crianças, tendo como objetivo central, alfabetizar todas os alunos da rede pública de ensino até os sete anos de idade.

O PAIC propõe um conjunto de ações para os cento e quarenta e oito municípios cearenses que assinaram o protocolo de intenções lançado em maio de 2007 e, o reafirmaram em fevereiro de 2009 através da assinatura dos prefeitos eleitos para gestão 2009 - 2012.

O programa PAIC está organizado em cinco eixos: Eixo da gestão municipal de educação; responsável no acompanhamento e andamento do Programa dentro do município e da consolidação dos objetivos alcançados. Eixo da alfabetização; docentes, discentes e comunidade escolar envolvido todos com o mesmo objetivo: encontrar subsídios que atenda as necessidades das crianças no processo alfabetizador. Eixo da avaliação externa; especialidade de diagnosticar o sucesso das crianças no processo de alfabetização e o desempenho do docente para que a criança tenha atingido o progresso. Eixo da educação infantil; universalizar o acesso e o atendimento das crianças de quatro e cinco anos na pré- 
escola. Eixo da literatura infantil e formação do leitor; aqui o principal objetivo é estimular nossas crianças a se tornarem leitores autônomos, mergulhando nos livros de histórias, gibis, dramatizações, contação de estórias, poesias, poemas. Pois disponibilizar livros às crianças em idade de alfabetização é uma das estratégias do PAIC para podermos formar leitores desde cedo. Essa estratégia foi adotada para aproximar os pequenos do acervo literário. E assim abraçar a idéia de incentivo a leituras existentes em cada cidade, formando em todo estado movimento pelo amor e dedicação aos livros, à literatura, à cultura e a educação.

O acompanhamento das ações do PAIC propõe sua efetivação em três instâncias: Coordenadoria Regional de Desenvolvimento da Educação - CREDE e SEDUC. Sendo que cada uma dessas instâncias tem suas responsabilidades a serem cumpridas conforme destacaremos: MUNICÍPIO - Através do acompanhamento interno às escolas e da consolidação das informações requeridas para o preenchimento de um manual de orientação e para o acompanhamento das ações do PAIC no município. Sendo que os instrumentais consolidados, deverão ser encaminhados bimestralmente a CREDE ou de acordo com solicitação dos mesmos.

Esses instrumentais se referem a situação e andamento da escola diagnosticando as situações de leitura, freqüência e registro da quantidade de títulos da literatura infantil lido pelos alunos de $1^{\circ}$ e $2^{\circ}$ ano do ensino fundamental no município durante o bimestre. Neste último cabe ressaltar a importância da formação dos cantinhos de leitura nas salas de aula, proposta destacada pelo eixo da literatura infantil e formação do leitor. Cabendo aqui ao professor o papel de contar histórias em sala de aula, de transportar as crianças para o fantástico mundo da leitura. O CREDE - através da gerência prestará apoio técnico e acompanhará a elaboração e execução do Plano de Trabalho Anual - PTA do PAIC, junto aos municípios que se localizam na região de abrangência da CREDE, consolidando as informações requeridas para o preenchimento de acompanhamento das ações do PAIC Regional, cujos instrumentais indicados deverão ser encaminhados bimestralmente a SEDUC. (MANUAL DE ORIENTAÇÃO PARA ACOMPANHAMENTO DAS AÇÕES DO PAIC, 2009, p.24).

O primeiro instrumental refere-se a situação de leitura das crianças, do $1^{\circ}$ e $2^{\circ}$ ano por turma. Essa situação de leitura segue os critérios de: leitor de texto com fluência, leitor de texto sem fluência, leitor de frases, leitor de palavras e não leitor. Após serem consolidados esses instrumentais os professores juntamente com a equipe do PAIC do município irão registrar as intervenções propostas par melhorar a situação de cada criança de acordo com a necessidade diagnosticada. A consolidação desse instrumental é feita pela escola e 
encaminhada a CREDE. Um outro instrumental refere-se a freqüência dos alunos de $1^{\circ}$ e $2^{\circ}$ anos do ensino fundamental também por turma. A freqüência consolidada será também encaminhada a CREDE. O último instrumental aqui destacado refere-se ao registro da quantidade de títulos de literatura infantil lido por alunos do $1^{\circ}$ e $2^{\circ}$ anos do ensino fundamental por turma; e consolidados pela escola bimestral.

Para cada acompanhamento de ações e metas há um instrumental a ser preenchido e consolidado abrangendo a escola como um todo para um alcance das ações estabelecidas pelo programa. Vale ressaltar que destacamos aqui apenas os que se referem ao acompanhamento da aprendizagem das crianças. SEDUC - através da Coordenadoria de Cooperação dos Municípios (COPEM), acompanhará as ações do PAIC em nível central, consolidando as informações bimestralmente recebidas pela CREDE do estado para armazená-las e gerar relatórios necessários à SEDUC. (MANUAL DE ORIENTAÇÃO PARA ACOMPANHAMENTO DAS AÇÕES DO PAIC, 2009, p.10).

A metodologia de acompanhamento tem como base as metas para o período de gestão 2009-2012. Essas metas devem ser apropriadas pela política do município e definidas de modo percentual o quanto o município pretende avançar em cada meta estabelecida no PTA(Plano de Trabalho Anual.) esse deve traduzir os esforços do município para atingir metas definidas para alfabetizar as crianças do município na idade certa estabelecida pelo PAIC.

O gerente municipal e sua equipe são responsáveis pelo acompanhamento do programa, uma vez que esse é monitorado pelas ações do PAIC e é uma das atribuições do gerente municipal. Por isso, julgamos importantes estarmos atentos a essas atribuições, como também socializá-las com as demais equipes que compõem a secretaria municipal de educação, destacou a gerente Maria Oliveira Lino.

Para o acompanhamento das metas do PAIC e Plano de Trabalho Anual- PTA do PAIC no município, partindo do diagnóstico e, em conformidade com as metas em cada eixo do programa, sendo que o gerente municipal deve coordenar o processo de construção do PTA do PAIC no município. Para isso, deve reunir-se com os gestores municipais, inclusive atentando para a definição dos recursos financeiros que serão alocados ao programa. (MANUAL DE ORIENTAÇÃO PARA ACOMPANHAMENTO DAS AÇÕES DO PAIC, 2009, p.11).

A gestão precisa definir metas, estratégias, formas de acompanhamento, mecanismos de avaliação. Pois sem o estabelecimento e a definição clara de onde quer chegar corre se o risco de não saber o rumo e o que urge ser realizado. As metas propostas pelo PAIC são 
importantes para direcionar esforço principal fator que contribuirá para o alcance do nosso alvo centro de todo processo educacional, a aprendizagem do aluno.

As principais metas propostas pelo PAIC estão relacionadas à elevação do Índice de Desenvolvimento da Educação Básica-IDEB e a dos resultados obtidos através do SPAECE Alfa. Netas metas serão consideradas os indicadores relacionados a: redução do abandono; reprovação; distorção idade/série; monitoramento da freqüência de professores, servidores e alunos; aprendizagem dos alunos; cumprimento dos dias letivos entre outros.

É importante ressaltar que essas metas estão relacionadas ao compromisso assinado pelo gestor municipal no termo de adesão ao PAIC.

Dentre elas podemos destacar:

a) A alfabetização de $100 \%$ das crianças até o final do $2^{\circ}$ ano do ensino fundamental, comprovado através da avaliação do SPAECE - Alfa;

b) Disseminação da cultura de avaliação externa no município como ferramenta para definição de políticas;

c) Estruturação de uma equipe de avaliação externa na secretaria municipal; implementação dos cantinhos de leitura em $100 \%$ das salas de aula do $1^{\circ}$ e $2^{\circ}$ anos do ensino fundamental e acompanhamento de $100 \%$ das crianças para que leiam no mínimo, cinco títulos de literatura infantil, durante cada ano letivo. Tendo como instrumento norteador de acompanhamento das ações do PAIC no município, feito pela SEDUC/CREDE. Esse instrumento é o PTA do município.

\section{Conclusão}

A realização deste trabalho buscou elucidar o desenvolvimento da leitura e escrita sob a perspectiva de uma alfabetização que não se limite ao ensino de uma mera decodificação de símbolos ou signos, mas, sobretudo, deva guiar-se por uma concepção ampla. Esta metodologia favorece uma interpretação significativa do mundo das letras e da relação que elas têm com a realidade. 
Alicerçado pelo estudo de diferentes autores relacionados ao processo de alfabetização verificou-se que a proposta pedagógica de ensino estabelecida pelo PAIC, refere-se ao ensino estruturado e sistematizado da leitura e da escrita, basicamente na classe de alfabetização e é grandemente facilitado com a utilização de textos especificamente voltados para esse fim.

A principal função da leitura em sala de aula é ensinar o aluno usar textos para aprender, compreendendo aquilo que ele lê, Daí a importância do conhecimento teórico da proposta educacional que se pretende levar a cabo em qualquer escola. Trata-se de mais uma fonte documental sobre o processo de aquisição da leitura e da escrita, através de novas metodologias educacionais, assunto que deve ser cotidianamente discutido, dadas as modificações técnicas e tecnológicas que tem surgido em nível global.

\section{Referências:}

BORTONI, Ricardo, Stella Maris. Pra ler unidade 13. fundescola.mec.gov.br

BRASIL. Ministério da Educação e do Desporto. Secretaria da Educação Fundamental. Parâmetros Curriculares Nacionais: introdução...Brasília, 1997.p. 69

CAPOVILLA, A e CAPOVILLA F. Alfabetização: método fônico. São Paulo: menon (4.ed) 2003.

CAPOVILLA, A e CAPOVILLA F. Otimizando a aquisição da linguagem escrita: comparação entre os métodos fônicos e global de alfabetização. Caderno de pedagogia, 2002.

CURI, C. R. J. A propósito da educação e do desenvolvimento no Brasil. In: educação e sociedade. Cortes e Morais. Nº, p.4 a 17.

FERREIRO, Emilia. Reflexões sobre Alfabetização. 18. ed: São Paulo: Cortez: autores associados, 1991.

FERREIRO, Emilia. Psicogênese da língua escrita .Porto Alegre: artes Médicas,1988.

GROSSI, Ester pillar. Didática da alfabetização - Rio de Janeiro: paz e terra, 1990.

MANUAL DE ORIENTAÇÃO PARA ACOMPANHAMENTO DAS AÇÕES DO PAIC, 2009.

OLIVEIRA, J. B. ABC do alfabetizador. Alfa educativa: instituto Alfa e Beto, 5a ed. 2007. 
VIGOTSKY, Lev Semenovick. Linguagem, desenvolvimento e aprendizagem: Leo Semenovick Vigotsky, Alexander Romanovick Lúria, Alex Leoniev. São Paulo: Ícone: Editora da Universidade de São Paulo. 1988.

WEIZ, Telma, Sanchez Ana. O diálogo entre o ensino e a aprendizagem. Ed. Ática, 2000.

Sobre a autora:

(1) Cícera Pereira da Silva é Educadora e Especialista em Psicologia Aplicada à Educação pela Universidade Regional do Cariri - URCA.

\section{Como citar este artigo (Formato ISO):}

SILVA, Cícera P. Desenvolvimento da leitura e da escrita através do Programa Alfabetização na Idade Certa - PAIC. Id on Line Revista de Psicologia, Novembro. 2009, vol.1, no.10, p.49-69. ISSN 1981-1189. 